\title{
Cardiac Myxoma with Cerebral Metastases and Chronic Lymphocytic Leukemia/Small Lymphocytic Lymphoma: A Case Report and Review
}

\author{
Jared A. Maas ${ }^{10} \quad$ Manuel Menes ${ }^{2}$ Vitaly Siomin ${ }^{3}$ \\ ${ }^{1}$ Department of Radiation Oncology, University of Alabama at \\ Birmingham, Hazelrig Salter Radiation Oncology Center, \\ Birmingham, Alabama, United States \\ 2 Department of Pathology, Baptist Health South Florida, \\ Miami, Florida, United States \\ ${ }^{3}$ Department of Neurosurgery, Baptist Health South Florida, \\ Miami, Florida, United States
}

\author{
Address for correspondence Jared A. Maas, MD, Department of \\ Radiation Oncology, University of Alabama at Birmingham, Hazelrig \\ Salter Radiation Oncology Center, 1719 6th Avenue South, \\ Birmingham, AL 35294, United States \\ (e-mail: jaredamaas@gmail.com).
}

J Neurol Surg Rep 2020;81:e1-e6.

\section{Introduction}

Primary cardiac tumors are rare, occurring in 0.02 to $2.8 \%$ of autopsy series; a plurality of these cases are cardiac myxomas, which account for 30 to $50 \%$ of primary cardiac tumors in pathologic series. ${ }^{1}$ The vast majority of cardiac myxomas - $283 \%$ of cases-occur in the left atrium, while $13 \%$ occur in the right atrium. ${ }^{1}$ Demographically, patients are diagnosed at a mean age of 50 with nearly a 2:1 female predominance. ${ }^{1}$ Myxomas are generally benign tumors ${ }^{1}$ that are thought to be derived from endocardial multipotent mesenchymal cells. ${ }^{2,3}$ However, they have a higher risk of recurrence in the setting of incomplete resection, multiple foci, and tumor embolism. $^{2}$ received

July 28, 2019

accepted

September 28, 2019
DOI https://doi.org/

10.1055/s-0039-3399570. ISSN 2193-6358. (c) 2020 Georg Thieme Verlag KG
Stuttgart · New York

License terms

(c) $(1) \$$ 
While the most common clinical presentation of cardiac myxomas is dyspnea secondary to congestive heart failure, ${ }^{4}$ as many as $50 \%$ of the reported cases of atrial myxomas present with complications due to embolization, and up to half of these cases present with neurologic manifestations. ${ }^{5}$ Among these neurologic manifestations, atrial myxomas can cause infarction, aneurysm, or rarely metastasis. ${ }^{5}$ To date, only 27 cases of cardiac myxoma metastasis to the brain have been reported, including the present case.

Primary cardiac lymphoma is also particularly rare, amounting to less than $2 \%$ of all primary cardiac tumors. ${ }^{3}$ The most common histological subtype of primary cardiac lymphoma is large B cell lymphoma. ${ }^{6}$ Most cases of primary cardiac lymphoma occur in immunocompromised patients. ${ }^{6}$ The outlook for these patients is generally poor-the median survival is 7 months after initial diagnosis. ${ }^{6}$ Primary cardiac lymphoma arising within cardiac myxoma is exceedingly rare with only 22 reported cases since 2009 , including the present case. $^{3,7}$

The present case is the first known case of myxoma metastases and lymphoma arising within myxoma occurring in the same patient. Additionally, it is the first known instance of a lymphoma arising within cardiac myxoma metastases rather than within the cardiac primary tumor.

\section{Case Report}

A 62-year-old male patient with a past medical history of hypertension, hypertrophic cardiomyopathy, and an episode of left arm numbness in April 2016 initially presented to the hospital with mild chest discomfort, left arm numbness, visual changes, and gait instability in June 2016. The patient underwent stroke workup including a magnetic resonance imaging (MRI) of the brain, which demonstrated hemorrhagic lesions to the brain and transesophageal echocardiography, which revealed a $4.2 \times 2.4 \mathrm{~cm}$ (centimeters) mass in the left atrium. Gross total resection of the cardiac lesion was performed under cardiopulmonary bypass through a right thoracotomy approach in July of 2016. The patient had an uneventful postoperative course. Echocardiography showed no evidence of residual tumor. Histopathologic examination confirmed a diagnosis of left atrial myxoma. In December 2016, the patient presented to the hospital with painful fingertip nodules. Following resection of these lesions, histopathologic evaluation proved that these lesions were myxomatous.

The patient returned to the hospital in June 2017, 12 months after his initial presentation, complaining of 2 weeks of weakness and clumsiness of the left upper extremity and episodes of blurred vision lasting 30 to 40 minutes several times a week. Repeat transesophageal echocardiogram showed no evidence of intracardiac recurrence. Brain MRI performed with and without contrast demonstrated enlarged heterogeneously enhancing hemorrhagic masses in the right posterior occipital-parietal region with increased vasogenic edema and mild mass-effect on the posterior horn of the right lateral ventricle (-Fig. 1). The dominant enlarging hemorrhagic lesion measured $36 \times 36 \times 37 \mathrm{~mm}$ (millimeter) and a second measured $18 \times 14 \times 12 \mathrm{~mm}$. Three other lesions from previous scans in the posterior frontal and parieto-occipital regions were decreasing or resolved. Image-guided right parieto-occipital craniotomy with neuromonitoring for resection of the dominant and three other lesions was performed. Four tan hemorrhagic soft tissue specimens were submitted for histopathologic evaluation, which demonstrated metastatic atrial myxoma and a small lymphocytic lymphoma/chronic lymphocytic leukemia arising (SLL/CLL) from within the metastatic atrial myxoma (-Fig. 1). The atypical predominantly perivascular small lymphocytic infiltrate within the tumor revealed a PAX (paired box gene) $-5+/ C D$ (cluster of differentiation)20-/CD5 +/CD3-/ CD23+ (partial)/BCL (B cell lymphoma)-6-/cyclin D1- immunophenotype on immunoperoxidase stains (-Fig. 1). These immunohistochemical results, together with the morphologic features, are consistent with CLL/SLL. There was no evidence of lymphoma outside the myxoma. Neither chemotherapy nor radiotherapy was administered.

Following the procedure, the patient recovered well. Postoperative MRI showed postoperative changes and no evidence of residual tumor. The patient was placed on levetiracetam prophylactically for 5 days. He initially reported worsening visual fields on postoperative day 1 , which partially resolved by postoperative day 2 . There were no other signs or symptoms. The patient was discharged on postoperative day 2 for close outpatient followup. As of a 48-month follow-up visit, the patient was doing well with continuous visual field improvement and no evidence of disease.

\section{Discussion}

There are 27 cases-including the present case-of a cardiac myxoma metastasizing to the brain reported in the literature (-Table 1). ${ }^{2}$ The authors are aware of only one other case of histopathologically proven CLL/SLL within a cardiac myxo$\mathrm{ma}^{8}$ and only 21 other cases of lymphomas within a cardiac myxoma (-Table 2 ). ${ }^{3,7}$ The present case also represents the first known instance of a lymphoma arising within a myxomatous cerebral metastasis.

As this is the first reported case of both cardiac myxoma metastases and lymphoma within a cardiac myxoma in the same patient, it is unclear if the presence of lymphoma is related to the metastatic potential of an otherwise usually benign tumor. Cardiac myxomas are thought to metastasize secondary to embolism prior to or during surgical handling. ${ }^{2}$ Despite this, embolic manifestations can be delayed months or even years. ${ }^{2,13,14}$ This patient's additional presentation with myxomatous involvement of the extremities 6 months after his initial presentation supports the theory of arterial embolization. Additionally, cardiac myxomas are known to secrete several inflammatory cytokines such as endothelin-1, interleukin-6, cysteine $\mathrm{X}$ cysteine cytokines, interleukin-8, and growth-related oncogene $\alpha .{ }^{46}$ It is also known that chronic inflammation in several inflammatory conditions is associated with the development of lymphoma. ${ }^{47}$ Therefore, a more parsimonious hypothesis is that the CLL/SLL arose within the cardiac myxoma metastases because of the chronic inflammatory state created by the 


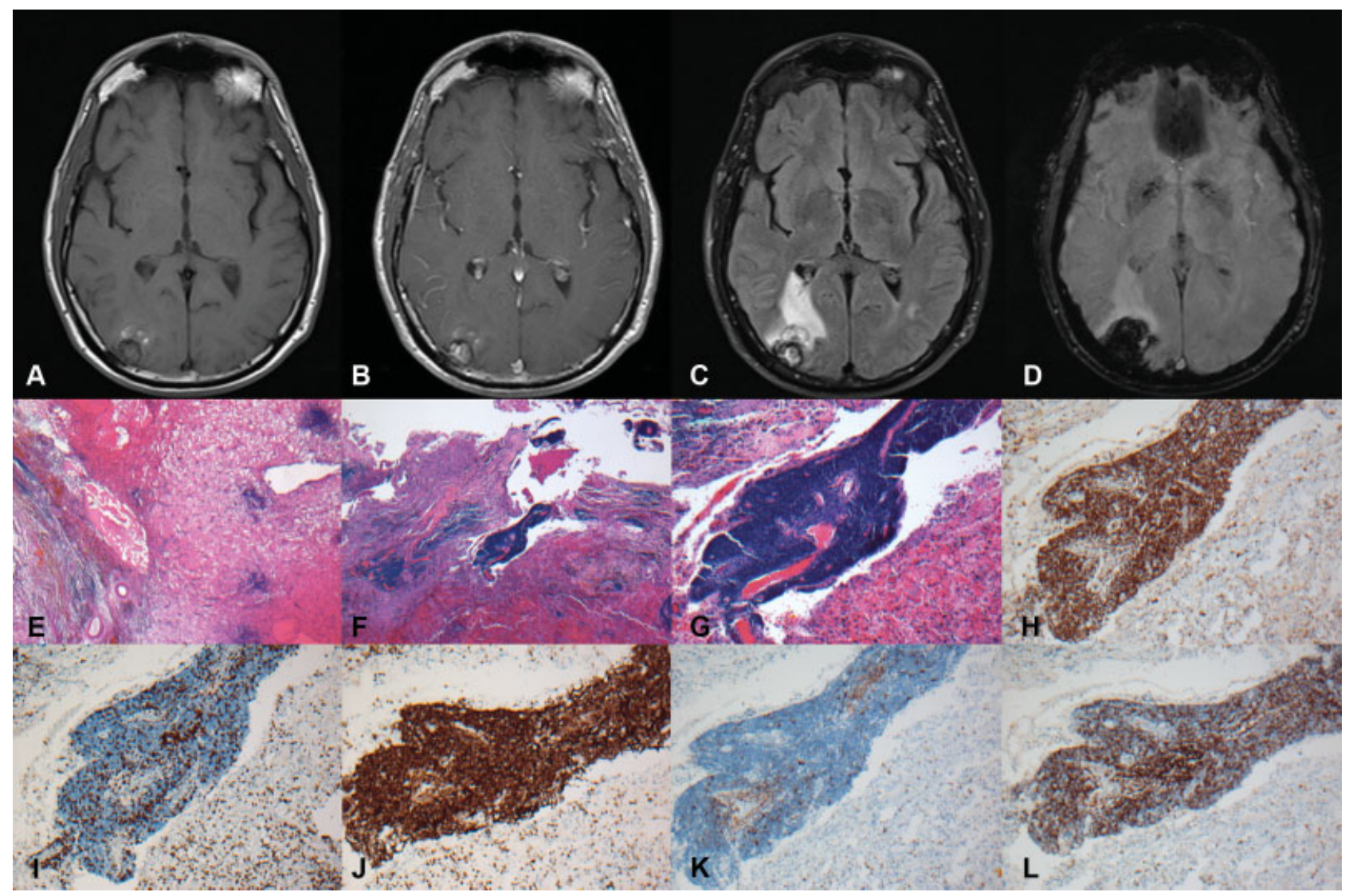

Fig. 1 A magnetic resonance imaging T1-weighted image prior to gadolinium administration, demonstrated a lesion in the parieto-occipital region (A). The T1-weighted image after gadolinium injection showed enhancement in the center of the mass (B). Fluid attenuation inversion recovery image showed perifocal edematous changes extending to the atrium and occipital horn of the right lateral ventricle (C). Gradient echo image amplified the artifact caused by hemorrhagic products in and around the mass (D). Microscopic examination at $2 x$ magnification reveals metastatic myxoma with dense lymphoid infiltrates ( $E$ and $F)$. Further examination at 10x magnification shows the lymphoid infiltrate within myxoma is tightly cuffing blood vessels $(G)$. Immunohistochemistry at $10 x$ magnification reveals Pax 5 stain positive in infiltrate indicating B cell lineage $(\mathrm{H})$, CD3 stain demonstrates only few T cells (I), CD5 stain expression in the B cell infiltrate (J), negative cyclin D1 stain excludes mantle cell lymphoma (K), and CD23 stain is positive in the small B cell infiltrate (L).

myxoma. ${ }^{3,39,41,43}$ Given the present case's neurologic manifestations prior to diagnosis of his cardiac myxoma, it is possible that the cerebral metastases were present several months before they were formerly diagnosed; if so, this longstanding inflammation would potentially allow for malignant transformation. Laird-Fick et $\mathrm{al}^{8}$ hypothesize that a shared genetic defect could be the link between myxoma and CLL/SLL, noting that abnormalities on chromosomes 12 and 17 as well as in the protein kinase-A pathway (including Carney complex gene mutations) have been associated with both tumors. A recent study showed that myxomas express elevated oncogenes and malignancy-related proteins such as c-MYC, p53, vimentin, and hypoxia-inducible factor $1-\alpha$ compared with normal heart tissue. This suggests that even though myxomas often clinically behave as benign tumors, they possess latent oncogenic and metastatic potential. ${ }^{48}$

It is also notable that lymphomas arising within cardiac myxomas do not behave like primary cardiac lymphomas. While most cases of primary cardiac lymphoma occur in immunocompromised patients, all 22 reported cases of lymphoma within myxoma occurred in immunocompetent patients (-Table 2). ${ }^{6}$ The prognosis for lymphoma arising within myxoma also seems to be better than the 7-month median survival associated with primary cardiac lymphoma (-Table 2). ${ }^{6}$ However, the sample size and follow-up data are limited so caution should be used when interpreting these data.

Because cardiac myxomas with cerebral metastases are extremely rare, there is no established gold standard treatment (-Table 1). Surgical excision seems to be the primary approach for diagnostic purposes, treatment of one to two isolated brain metastases, or treatment when one of several lesions is life-threatening. ${ }^{10,14}$ Radiation therapy can be used as a possible alternative treatment in patients with multiple metastases or as a supplementary treatment for patients who do not experience resolution with surgery alone., ${ }^{2,12-14,18}$ Most often, radiotherapy consisted of palliative whole brain radiation at 25 to $30 \mathrm{~Gy}$ (Gray), ${ }^{2,13,14}$ but doses as high as $40.8^{12}$ and $50 \mathrm{~Gy}^{18}$ have been attempted with positive results. Postoperative chemoradiotherapy using ifosfamide and doxorubicin and postoperative chemotherapy using doxorubicin alone have been attempted in two cases with positive and equivocal results, respectively. ${ }^{2,18}$ 
e4 Cardiac Myxoma, Cerebral Metastases, and CLL/SLL Maas et al.

Table 1 Reported cases of histopathologically proven cardiac myxoma metastasizing to the brain ${ }^{a}$

\begin{tabular}{|c|c|c|c|c|c|c|c|c|c|}
\hline Case & Report (reference) & Year & Age & $\begin{array}{l}\text { Interval to } \\
\text { recurrence } \\
\text { (months) }\end{array}$ & $\begin{array}{l}\text { Other } \\
\text { recurrent } \\
\text { sites }\end{array}$ & $\begin{array}{l}\text { Surgery } \\
\text { for brain } \\
\text { lesions }\end{array}$ & RT & CT & $\begin{array}{l}\text { Outcome } \\
\text { follow-up } \\
\text { (months) }\end{array}$ \\
\hline 1 & Maas [our case] & 2019 & 62 & 12 & Fingertips & Yes & No & No & NED48 \\
\hline 2 & Rose et al case $1^{2}$ & 2016 & 44 & 5 & No & No & Yes & No & DOD17 \\
\hline 3 & Rose et al case $2^{2}$ & 2016 & 52 & 0 & No & No & No & Yes & AWD63 \\
\hline 4 & 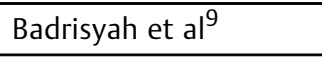 & 2012 & 15 & 36 & No & Yes & No & No & NED72 \\
\hline 5 & Radoi et al ${ }^{10}$ & 2012 & 45 & 18 & No & Yes & No & No & AWD12 \\
\hline 6 & Kumar et al ${ }^{11}$ & 2011 & 30 & 24 & No & Yes & No & No & $?$ \\
\hline 7 & Suzuki et al ${ }^{12}$ & 2008 & 68 & 6 & No & Yes & Yes & No & $?$ \\
\hline 8 & Moiyadi et al ${ }^{13}$ & 2007 & 35 & 48 & No & Yes & Yes & No & AWD6 \\
\hline 9 & Altundag et $\mathrm{al}^{14}$ & 2005 & 41 & 15 & No & Yes & Yes & No & AWD63 \\
\hline 10 & Acikel et al ${ }^{15}$ & 2004 & 58 & 0 & No & No & No & No & $?$ \\
\hline 11 & Hirundayaraj et al ${ }^{16}$ & 2004 & 50 & -1 & No & Yes & No & No & $?$ \\
\hline 12 & Hou et $\mathrm{al}^{17}$ & 2001 & 37 & 10 & Bone & No & No & No & DOD12 \\
\hline 13 & Bernet et al ${ }^{18}$ & 1998 & 31 & 2 & Muscle, lung & Yes & Yes & Yes & NED120 \\
\hline 14 & Scarpelli et al ${ }^{19}$ & 1997 & 64 & 144 & No & Yes & No & No & $?$ \\
\hline 15 & Samaratunga et $\mathrm{al}^{20}$ & 1994 & 60 & -7 & No & Yes & No & No & NED21 \\
\hline 16 & Kanda et $\mathrm{al}^{21}$ & 1994 & 70 & -7 & No & Yes & No & No & NED9 \\
\hline 17 & Chozick et al $^{22}$ & 1992 & 61 & 8 & No & Yes & No & No & NED72 \\
\hline 18 & Todo et $\mathrm{al}^{23}$ & 1992 & 32 & 10 & Jejenum & No & No & No & DOD10 \\
\hline 19 & Kotani et al ${ }^{24}$ & 1991 & 48 & 3 & $\begin{array}{l}\text { Soft tissue, } \\
\text { aorta }\end{array}$ & Yes & No & No & DOD53 \\
\hline 20 & $\mathrm{Ng}$ et $\mathrm{al}^{25}$ & 1990 & 54 & 6 & No & Yes & No & No & AWD18 \\
\hline 21 & de Morais et al ${ }^{26}$ & 1988 & 73 & 0 & $\begin{array}{l}\text { Kidney, } \\
\text { pancreas, } \\
\text { stomach }\end{array}$ & No & No & No & DOD1 \\
\hline 22 & Bazin et al ${ }^{27}$ & 1987 & 56 & 48 & No & Yes & No & No & $?$ \\
\hline 23 & Kadota et al ${ }^{28}$ & 1987 & 44 & 3 & Skin & Yes & No & No & $?$ \\
\hline 24 & Markel et a ${ }^{29}$ & 1986 & 18 & 30 & Bone & No & No & No & AWD39 \\
\hline 25 & Seo et al ${ }^{30}$ & 1980 & 36 & 96 & Bone & Yes & No & No & AWD120 \\
\hline 26 & Budzilovich et al ${ }^{31}$ & 1979 & 52 & 0 & No & No & No & No & DOD1 \\
\hline 27 & Rankin and DeSousa ${ }^{32}$ & 1978 & 44 & 96 & No & Yes & No & No & AWD120 \\
\hline
\end{tabular}

Abbreviations: AWD, alive with disease; CT, chemotherapy; DOD, died of disease; NED, no evidence of disease; RT, radiotherapy.

${ }^{a}$ Adapted from Rose et al 2016, ${ }^{2}$ Moiyadi et al $2007,{ }^{13}$ and Altdung et al $2005^{14}$; added Kumar et al ${ }^{11}$ and Suzuki et al. ${ }^{12}$

Note: "?" refers to unknown outcome.

Additionally, the standard management of lymphomas arising within cardiac myxomas has not yet been determined because the cases occur so infrequently ( - Table 2 ). While 7 out of the 22 cases have been treated with postoperative chemotherapy, it is not clear if chemotherapy is needed in the setting of disease confined within the myxoma status post total resection. ${ }^{3}$ One out of the 22 cases died as a result of chemotherapy-induced neutropenic fever and opportunistic pneumonia ${ }^{42}$ and three other cases that did not receive postoperative chemotherapy had no evidence of disease recurrence at a six-, ${ }^{40}$ ten-, ${ }^{7}$ and eleven- ${ }^{36}$ year follow-up. Furthermore, it is possible that the lymphoma remains localized completely within the myxoma, and if so, it may be prudent to withhold postsurgical chemotherapy until the patient develops a recurrence. ${ }^{3,7,39-41,43}$ As of now, the patient presented in this report has been treated with surgery alone.

Further characterization of cardiac myxomas through molecular markers might allow for a better understanding of the pathogenesis of cardiac myxoma and myxomatous metastases as well as more rapid diagnosis of this rare disease. Future studies examining the potential for a related pathogenesis between cardiac myxoma and CLL/SLL might also improve the generalizable knowledge surrounding these two diseases. Additional case reports and follow-up may elucidate the most appropriate treatments for cardiac 
Cardiac Myxoma, Cerebral Metastases, and CLL/SLL Maas et al. e5

Table 2 Reported cases of histopathologically proven lymphoma within cardiac myxoma ${ }^{a}$

\begin{tabular}{|c|c|c|c|c|c|c|c|c|c|}
\hline Case & Report (Reference) & Year & Age & Sex & Location & Phenotype & $\begin{array}{l}\text { Immune } \\
\text { status }\end{array}$ & Chemotherapy & $\begin{array}{l}\text { Outcome } \\
\text { follow-up } \\
\text { (months) }\end{array}$ \\
\hline 1 & Maas (our case) & 2019 & 62 & M & $\begin{array}{l}\text { Intracranial } \\
\text { met from left } \\
\text { atrium }\end{array}$ & CLL & IP & None & NED48 \\
\hline 2 & Garces and Sriganeshan ${ }^{33}$ & 2019 & 50 & M & Left atrium & FA-DLBCL & IP & None & NED65 \\
\hline 3 & Park et $\mathrm{al}^{34}$ & 2018 & 44 & M & $\begin{array}{l}\text { Left atrium, } \\
\text { Right CFA } \\
\text { embolus }\end{array}$ & $\mathrm{nGC-DLBCL}$ & IP & $\mathrm{R}-\mathrm{CHOP} \times 6$ & None \\
\hline 4 & Yan et al case $1^{7}$ & 2017 & 46 & $\mathrm{~F}$ & Left atrium & nGC-DLBCL & IP & None & NED120 \\
\hline 5 & Yan et al case $2^{7}$ & 2017 & 61 & $\mathrm{~F}$ & Left atrium & GC-DLBCL & IP & None & NED84 \\
\hline 6 & Yan et al case $3^{7}$ & 2017 & 54 & M & Left atrium & nGC-DLBCL & IP & None & NED7 \\
\hline 7 & Yan et al case $4^{7}$ & 2017 & 46 & $\mathrm{~F}$ & Left atrium & nGC-DLBCL & IP & None & NED3 \\
\hline 8 & Jiang et $\mathrm{al}^{35}$ & 2017 & 63 & M & Left atrium & nGC-DLBCL & IP & None & NED7 \\
\hline 9 & Boyer et al case $1^{36}$ & 2017 & 54 & $\mathrm{~F}$ & Left atrium & nGC-DLBCL & IP & NA & NED130 \\
\hline 10 & Boyer et al case $2^{36}$ & 2017 & 55 & $\mathrm{~F}$ & Left atrium & nGC-DLBCL & IP & None & $\mathrm{DOC2}^{\mathrm{b}}$ \\
\hline 11 & Boyer et al case $3^{36}$ & 2017 & 54 & $M$ & Left atrium & nGC-DLBCL & IP & None & DOD26 \\
\hline 12 & Pineda et $\mathrm{a}^{37}$ & 2015 & 50 & M & Left atrium & $\mathrm{HGBCL}$ & IP & NA & None \\
\hline 13 & Aguilar et al ${ }^{38}$ & 2015 & 52 & M & Left atrium & nGC-DLBCL & IP & None & NED42 \\
\hline 14 & Liu et $\mathrm{al}^{3}$ & 2015 & 52 & M & Left atrium & nGC-DLBCL & IP & None & NED3 \\
\hline 15 & Tapan et $a^{39}$ & 2015 & 49 & M & Left atrium & nGC-DLBCL & IP & $\mathrm{CHOP} \times 6$ & NED12 \\
\hline 16 & Laird-Fick et al ${ }^{8}$ & 2014 & 56 & $\mathrm{~F}$ & Left atrium & CLL & IP & $\mathrm{FCR} \times \mathrm{NA}$ & AWD18 ${ }^{d}$ \\
\hline 17 & Bartoloni et al ${ }^{40}$ & 2013 & 55 & $\mathrm{~F}$ & Left atrium & ALBP & IP & None & NED72 \\
\hline 18 & Svec et al ${ }^{41}$ & 2012 & 60 & $\mathrm{~F}$ & Left atrium & nGC-DLBCL & IP & $\mathrm{CHOP} \times 6$ & NED7 \\
\hline 19 & Loong et al ${ }^{42}$ & 2010 & 70 & $\mathrm{~F}$ & Left atrium & nGC-DLBCL & IP & CEOP $\times 4$ & $\mathrm{DOC5}^{\mathrm{e}}$ \\
\hline 20 & Dimitrova et al ${ }^{43}$ & 2010 & 51 & M & Left atrium & GC-DLBCL & IP & $\mathrm{CHOP} \times 6$ & None \\
\hline 21 & White et $\mathrm{al}^{44}$ & 2010 & 75 & $\mathrm{~F}$ & Left atrium & PLL & IP & NA & None \\
\hline 22 & Bagwan et al ${ }^{45}$ & 2009 & 81 & $\mathrm{~F}$ & Left atrium & GC-DLBCL & IP & $\mathrm{R}-\mathrm{CHOP} \times \mathrm{NA}$ & None \\
\hline
\end{tabular}

Abbreviations: ALBP, atypical lymphoid B-cell proliferation; AWD, alive with disease; CFA, common femoral artery; CLL, chronic lymphocytic leukemia; DOC, died of other cause; DOD, died of disease; FA-DLBCL, fibrin associated diffuse large B-cell lymphoma; FCR, fludarabine, cyclophosphamide, and rituximab; HGBCL, high grade B-cell lymphoma; IP, immunocompetent patient; NA, not available. R-CHOP, rituximab cyclophosphamide, doxorubicin, vincristine, and prednisone; NED, no evidence of lymphoma recurrence or dissemination; nGC-DLBCL, nongerminal center diffuse large B-cell lymphoma; PL, plasmacytic lymphoma; R-CEOP, rituximab, cyclophosphamide, epirubicin, vincristine, and prednisone. ${ }^{a}$ Adapted from Yan et al $2017^{7}$ and Liu et al $2015^{3}$; added Maas et al (our case), Jiang et al, ${ }^{35}$ Pineda et al, ${ }^{37}$ Garces et al, ${ }^{33}$ and Park et al. ${ }^{34}$

${ }^{\mathrm{b}}$ Cardiomegaly, myocardial infarction.

'Embolic strokes.

'Local recurrence at 18 months after no chemotherapy; began FCR chemotherapy, with clinical remission.

${ }^{\mathrm{e} C}$ Complications of chemotherapy.

myxoma metastases and lymphoma with cardiac myxoma leading to better patient outcomes.

Conflicts of Interest

The authors declare that there are no conflicts of interest. This research did not receive any specific grant from funding agencies in the public, commercial, or not-forprofit sectors.

\section{References}

1 Kuon E, Kreplin M, Weiss W, Dahm JB. The challenge presented by right atrial myxoma. Herz 2004;29(07):702-709
2 Rose D, Papa A, Tomao S, Greco E, Zacharias J. Cerebral metastases in patients with left atrial myxoma. J Card Surg 2016;31(05): 289-293

3 Liu X, Liu P, Li J. EBV + diffuse large B-cell lymphoma arising within atrial myxoma in Chinese immunocompetent patient. Int J Clin Exp Pathol 2015;8(02):2159-2164

4 Shimono T, Makino S, Kanamori Y, Kinoshita T, Yada I. Left atrial myxomas. Using gross anatomic tumor types to determine clinical features and coronary angiographic findings. Chest 1995;107 (03):674-679

5 Desousa AL, Muller J, Campbell R, Batnitzky S, Rankin L. Atrial myxoma: a review of the neurological complications, metastases, and recurrences. J Neurol Neurosurg Psychiatry 1978;41(12): $1119-1124$ 
6 Miguel CE, Bestetti RB. Primary cardiac lymphoma. Int J Cardiol 2011;149(03):358-363

7 Yan J, Luo D, Zhang F, et al. Diffuse large B cell lymphoma associated with chronic inflammation arising within atrial myxoma: aggressive histological features but indolent clinical behaviour. Histopathology 2017;71(06):951-959

8 Laird-Fick H, Tiwari A, Narayanan S, Qin Y, Vodnala D, Bhutani M. A case of comorbid myxoma and chronic lymphocytic leukemia: not just a coincidence? Case Rep Oncol Med 2014;2014:142746

9 Badrisyah I, Saiful R, Rahmat H, Naik VR, Tan YC. Brain metastasis of atrial myxoma: case report. Med J Malaysia 2012;67(06):613-615

10 Radoi MP, Stefanescu F, Arsene D. Brain metastases and multiple cerebral aneurysms from cardiac myxoma: case report and review of the literature. Br J Neurosurg 2012;26(06):893-895

11 Kumar A, Deopujari CE, Karmarkar VS. A rare diagnosis of multiple hemorrhagic metastases in brain. J Postgrad Med 2011;57(03): 214-217

12 Suzuki R, Watanabe T, Hirayama R, et al. [Case with cardiac myxoma causing cerebral metastasis after cardiac tumor resection]. Kyobu Geka 2008;61(06):456-459

13 Moiyadi AV, Moiyadi AA, Sampath S, et al. Intracranial metastasis from a glandular variant of atrial myxoma. Acta Neurochir (Wien) 2007;149(11):1157-1162

14 Altundag MB, Ertas G, Ucer AR, et al. Brain metastasis of cardiac myxoma: case report and review of the literature. J Neurooncol 2005;75(02):181-184

15 Acikel M, Yekeler I, Ates A, Erkut B. A giant left atrial myxoma: an unusual cause of syncope and cerebral emboli. Int J Cardiol 2004; 94(2-3)325-326

16 Hirudayaraj P, Arya B, Suvarna SK, Payne G, Palaniswamy A. Myxomatous meningeal tumour: a case of "metastatic" cardiac myxoma. Int J Cardiol 2004;96(03):471-473

17 Hou YC, Chang S, Lo HM, Hsiao CH, Lin FY. Recurrent cardiac myxoma with multiple distant metastasis and malignant change. J Formos Med Assoc 2001;100(01):63-65

18 Bernet F, Stulz PM, Carrel TP. Long-term remission after resection, chemotherapy, and irradiation of a metastatic myxoma. Ann Thorac Surg 1998;66(05):1791-1792

19 Scarpelli M, Montironi R, Ricciuti R, Vecchioni S, Pauri F. Cardiac myxoma with glandular elements metastatic to the brain 12 years after the removal of the original tumor. Clin Neuropathol 1997;16 (04):190-194

20 Samaratunga H, Searle J, Cominos D, Le Fevre I. Cerebral metastasis of an atrial myxoma mimicking an epithelioid hemangioendothelioma. Am J Surg Pathol 1994;18(01):107-111

21 Kanda T, Sakamaki T, Murata K. A cardiac myxoma with interleukin-6 production and cerebral metastasis. Int J Cardiol 1994;45 (02):144-146

22 Chozick BS, Ambler MW, Stoll J Jr. Malignant astrocytoma six years after the resection of a cerebral metastatic cardiac myxoma: case report. Neurosurgery 1992;30(06):923-926, discussion 926-927

23 Todo T, Usui M, Nagashima K. Cerebral metastasis of malignant cardiac myxoma. Surg Neurol 1992;37(05):374-379

24 Kotani K, Matsuzawa Y, Funahashi T, et al. Left atrial myxoma metastasizing to the aorta, with intraluminal growth causing renovascular hypertension. Cardiology 1991;78(01):72-77

$25 \mathrm{Ng}$ HK, Poon WS. Cardiac myxoma metastasizing to the brain. Case report. J Neurosurg 1990;72(02):295-298

26 de Morais C, Falzoni R, Alves VA. Myocardial infarct due to a unique atrial myxoma with epithelial-like cells and systemic metastases. Arch Pathol Lab Med 1988;112(02):185-190

27 Bazin A, Peruzzi P, Baudrillard JC, Pluot M, Rousseaux P. [Cardiac myxoma with cerebral metastases]. Neurochirurgie 1987;33(06): 487-489

28 Kadota T, Imakita S, Mitomo M, et al. Metastatic brain tumor of atrial myxoma. Neuroradiology 1987;29(02):218
29 Markel ML, Armstrong WF, Waller BF, Mahomed Y. Left atrial myxoma with multicentric recurrence and evidence of metastases. Am Heart J 1986;111(02):409-413

30 Seo IS, Warner TF, Colyer RA, Winkler RF. Metastasizing atrial myxoma. Am J Surg Pathol 1980;4(04):391-399

31 Budzilovich G, Aleksic S, Greco A, Fernandez J, Harris J, Finegold M. Malignant cardiac myxoma with cerebral metastases. Surg Neurol 1979;11(06):461-469

32 Rankin LI, DeSousa AL. Metastatic atrial myxoma presenting as intracranial mass. Chest 1978;74(04):451-452

33 Garces S, Sriganeshan V. Fibrin-associated diffuse large B-cell lymphoma confined to a cardiac myxoma. Blood 2019;133(08):882

34 Park CK, Cho YA, Kim M, Shim HS. Malignant lymphoma arising in cardiac myxoma, presenting with peripheral arterial emboli. Cardiovasc Pathol 2018;32:26-29

35 Jiang YY, Jiang CW, Wang LP. [Epstein-Barr virus-positive large Bcell lymphoma arising within atrial myxoma: report of a case]. Zhonghua Bing Li Xue Za Zhi 2017;46(04):273-274

36 Boyer DF, McKelvie PA, de Leval L, et al. Fibrin-associated EBVpositive large B-cell lymphoma: an indolent neoplasm with features distinct from diffuse large B-cell lymphoma associated with chronic inflammation. Am J Surg Pathol 2017;41(03):299-312

37 Pineda AM, Mihos CG, Nascimento FO, Santana O, Lamelas J, Beohar N. Coronary embolization from a left atrial myxoma containing malignant lymphoma cells. Tex Heart Inst J 2015;42 (06):565-568

38 Aguilar C, Beltran B, Quiñones P, et al. Large B-cell lymphoma arising in cardiac myxoma or intracardiac fibrinous mass: a localized lymphoma usually associated with Epstein-Barr virus? Cardiovasc Pathol 2015;24(01):60-64

39 Tapan U, Pestana JB, Lee JC, Lerner A. Epstein-Barr virus-associated diffuse large B-cell lymphoma arising in atrial myxoma: a proposal for a modified therapeutic approach. Leuk Lymphoma 2015;56(02):505-507

40 Bartoloni G, Pucci A, Giorlandino A, et al. Incidental Epstein-Barr virus associated atypical lymphoid proliferation arising in a left atrial myxoma: a case of long survival without any postsurgical treatment and review of the literature. Cardiovasc Pathol 2013;22 (03): e5-e10

41 Svec A, Rangaiah M, Giles M, Jaksa R, McAulay KA. EBV+ diffuse large B-cell lymphoma arising within atrial myxoma. An example of a distinct primary cardiac EBV + DLBCL of immunocompetent patients. Pathol Res Pract 2012;208(03):172-176

42 Loong F, Chan AC, Ho BC, et al. Diffuse large B-cell lymphoma associated with chronic inflammation as an incidental finding and new clinical scenarios. Mod Pathol 2010;23(04):493-501

43 Dimitrova KR, Hoffman DM, Geller CM, et al. Malignant B-cell lymphoma arising in a large, left atrial myxoma. Ann Thorac Surg 2010;89(02):626-629

44 White RW, Hirst NA, Edward S, Nair UR. Plasmacytoid lymphoma within a left atrial myxoma: a rare coincidental dual pathology. Interact Cardiovasc Thorac Surg 2010;10(01):140-141

45 Bagwan IN, Desai S, Wotherspoon A, Sheppard MN. Unusual presentation of primary cardiac lymphoma. Interact Cardiovasc Thorac Surg 2009;9(01):127-129

46 Sakamoto H, Sakamaki T, Sumino H, et al. Production of endothelin- 1 and big endothelin- 1 by human cardiac myxoma cellsimplications of the origin of myxomas-. Circ J 2004;68(12): $1230-1232$

47 Smedby KE, Baecklund E, Askling J. Malignant lymphomas in autoimmunity and inflammation: a review of risks, risk factors, and lymphoma characteristics. Cancer Epidemiol Biomarkers Prev 2006;15(11):2069-2077

48 Pacheco-Velázquez SC, Gallardo-Pérez JC, Díaz D, et al. Heart myxoma develops oncogenic and metastatic phenotype. J Cancer Res Clin Oncol 2019;145(05):1283-1295 